\title{
Zeotropic Refrigerant Mixtures in Vapour Compression Refrigeration Systems - Issues and Implications
}

\author{
Leelananda Rajapaksha
}

\begin{abstract}
Use of zeotropic refrigerant mixtures introduce a number of novel issues related to vapour compression systems used in refrigeration and air conditioning industry. Certain attributes associated with evaporation and condensation behaviours of zeotropic mixtures are responsible for most of these. This paper discusses how the mixture attributes influence the established practices, design and operation of conventional vapour compression systems.
\end{abstract}

Keywords: zeotropes, azeotropes, temperature glide, composition sift, non-linearity

\section{Introduction}

Before 1980s, chlorofluorcarbons (CFC) and hydrochlorofluorocarbons (HCFC) took the leading stand as the most suited category of working fluids for refrigeration and air conditioning (RAC) applications. However, with the advent of environmental implications associated with the CFCs and HFCFs, presently a mechanism for gradual global cut down on the use of these substances is in place. Various fluids; for example hydrocarbons (HCs), organic and inorganic fluids, hydrofluorocarbons (HFCs), and blends of certain HCFCs and HFCs are considered as replacements. To obtain working fluids that a) do not damage the environment and b) match the thermal-physical characteristics of CFCs or HCFCs being replaced, mixing of suitable refrigerants (HFCs, HCFCs and HCs) became a preferred concept.

Unlike with pure refrigerants, with many mixtures the phase changing process is nonisothermal, and the composition of mixture does not remain constant during condensation and evaporation. This situation has left the RAC industry with numerous issues to deal with. Design norms and operational guidelines, component and lubricant selection procedures etc., are a few to mention. Further, non-isothermal phase change behaviour of mixtures creates ambiguity in selecting heat exchangers or compressors from manufacturers' catalogue based on a single temperature [1]. Changes in mixture composition causes variations in capacity, flow temperatures and coefficient of performance (COP) etc., compared to the original design [2].
Invariably, the change over from pure to mixture refrigerants demand reassessing and revising many established practices associated with vapour compression systems. Thermodynamic and heat transfer behaviour is one of the important aspects in this context. Further, influences of two special attributes of mixtures; temperature glide (TG) and composition shift (CS), too require detailed attention. These two attributes exert significant influence on heat transfer behaviour [3] to the extent that errors of omitting the effects in heat exchanger design can be substantial. On the other hand, with appropriate system design, the two attributes contribute towards improving, and optimizing system performance. A conceptual discussion on issues and implications of using refrigerant mixtures in vapour compression systems forms the theme for this paper.

\section{Background - refrigerant mixtures}

Evaporation or condensation of a pure fluid is isothermal. However, a mixture with two or more components exhibits non-isothermal phase change behaviour. For example, start and finish of evaporation of a mixture occur at bubble point and dew point temperature respectively. Fig. 1 shows this behaviour for a binary mixture. During phase changing process, the vapour phase is enriched with more volatile components, while the liquid phase is depleted of the same component(s) of the mixture.

Dr. Leelananda Rajapaksha, BSc.Eng. (First class Hons. Pemdeniya). M.Eng. (AIT, Bangksk), PhD (University of London, UCL) is a Senior

Lecturer altached to the Department of Mechaniral Engineering. Faculty of Engineering, University of Peradeniya. 
At a given pressure and composition, the difference between the dew point and the bubble point temperatures is defined as the temperature glide (TG).

When different refrigerant mixtures are considered based on their phase changing process, two main groups; azeotropes and zeotropes (also termed non-azeotropes), can be identified.

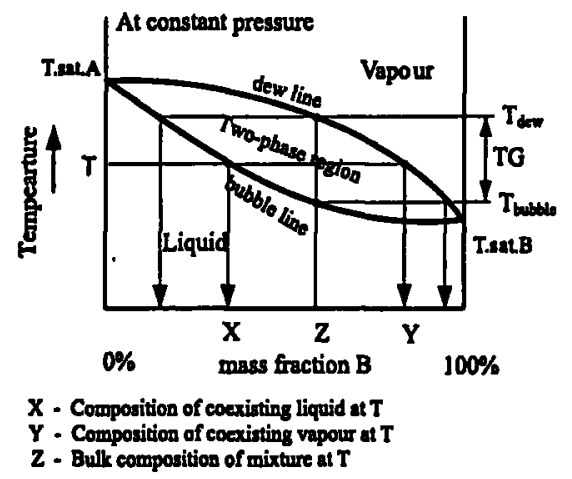

Fig. 1 : Phase changing process of a binary mixture

When in equilibrium, azeotropes exhibit the same liquid and vapour phase compositions and can be considered single component refrigerants for practical purposes [4]. In these mixtures, a unique phenomenon occurs along specific locus of pressure, temperature and composition such that the vapour and liquid compositions during phase change remain relatively unchanged. Examples of this kind of mixtures are well known R500 (i.e. R12+R152a), R502 (i.e. R22+R115) used in freezing and transport refrigeration applications. Temperature glides of these mixtures are less than $0.25 \mathrm{oC}$ in the range of pressures found in common vapour compression systems.

On the other hand, zeotropic mixtures show different vapour and liquid compositions when in equilibrium. This is a direct result of nonsimilar boiling points of the individual refrigerants that make up a zeotrope [5]. During phase change, different boiling points of the constituents promote preferential boiling (or condensation) of certain components relative to the others. This leads to a change (or shift) in the composition of the phase changing mixture. Associated with the composition shift are the changes of the dew (Tdew) and the bubble (Tbub) point temperatures of the remaining mixture. This results in a non-isothermal phase change occurring within dew and bubble point temperatures.
The magnitude of temperature glide of azeotropic refrigerants generally depends on the boiling points of the components and the composition, and decreases with increasing pressure. The magnitude of composition shift during zeotropic phase change can be estimated using the corresponding composition values $(Z-P$ and $Z$ $Q$. Fig. 1) along the bubble and the dew lines respectively for a binary mixture. Table 1 presents composition details and temperature glides of few selected mixtures presently used to replace common CFCs and HCFCs indicated.

Table 1 : Refrigerant mixtures replacing

\begin{tabular}{|c|c|c|c|}
\hline Mixture & $\begin{array}{l}\text { Components and } \\
\text { mass fraction \% }\end{array}$ & $\begin{array}{l}\text { Replaced } \\
\text { CFC/HCFC }\end{array}$ & $\begin{array}{l}\text { TG } \\
\left({ }^{\circ} \mathrm{C}\right)\end{array}$ \\
\hline $\mathrm{R} 409 \mathrm{~A}$ & $\begin{array}{l}\text { R22/R124/R142b } \\
(60 / 25 / 15)\end{array}$ & $\mathrm{R} 12$ (CFC) & 7.89 \\
\hline $\mathrm{R} 401 \mathrm{~A}$ & $\begin{array}{l}\text { R22/R152a/R124 } \\
(53 / 13 / 34)\end{array}$ & $\mathrm{R} 12$ (CFC) & 5.59 \\
\hline $\mathrm{R} 407 \mathrm{C}$ & $\begin{array}{l}\text { R32/R125/R134a } \\
(23 / 25 / 52)\end{array}$ & R22 (HCFC) & 7.09 \\
\hline R410A & R32/R125 (50/50) & R22 (HCFC) & 0.05 \\
\hline R401B & $\begin{array}{l}\mathrm{R} 22 / \mathrm{R} 152 \mathrm{a} / \mathrm{R} 124 \\
(61 / 11 / 28)\end{array}$ & $\begin{array}{l}\mathrm{R} 500 \\
(\mathrm{CFC}+\mathrm{HFC})\end{array}$ & 4.95 \\
\hline
\end{tabular}

Note: $\mathrm{TG}=\mathrm{T}_{\text {dew }}-\mathrm{T}_{\text {bub }}$ presented in table 1 at $100 \mathrm{kPa}$

\section{Implications and influences of mixture behaviour}

\subsection{Temperature glide matching}

Mixtures with significant TG (about $5^{\circ} \mathrm{C}$ or larger) offer a theoretical potential to improve the performance and energy efficiency of vapour compression systems. The approach is to match the temperature profiles of the refrigerant and the heat transfer fluid (HTF) in a counter flow configuration, Fig. 2. This measure allows maintaining relatively constant and more importantly a small temperature difference, $\mathrm{dT}$, between the refrigerant and the HTF streams. This phenomenon is known as glide matching and it reduces the irreversibility of heat transfer process; improving the performances.

However, a perfect glide matching can be achieved only in certain heat exchanger geometries such as shell and tube, concentric tubes, flat plate heat exchangers etc. Compact heat 
exchangers used in certain vapour compression applications do not meet strict counter flow conditions so that the benefits of glide matching may not be achieved completely.

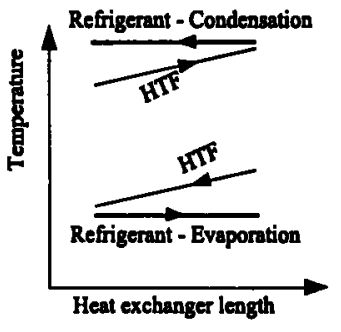

(a) (a)

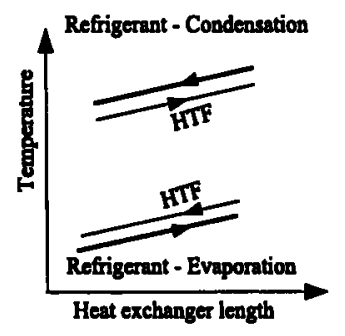

Fig. 2 : Heat exchanger temperature profiles during phase change of (a) pure refrigerant, (b) zeotrpic refrigerant mixture with glide matching

In addition, indirect advantages of glide matching are that (1) compressor will be working across a relatively reduced pressure range improving the COP, (2) relatively higher flow temperatures can be achieved using appropriate mixtures at relatively smaller compression work compared to a CFC refrigerant based system delivering similar capacity and flow temperature. However, the use of adequately sized heat exchangers is an important prerequisite for glide-matched systems, as smaller dTs invariably necessitate larger heat transfer areas to deliver required capacity.

Water, water/glycol mixture, átmospheric air can be considered as suitable HTFs for glide matching in the evaporator and the condenser of vapour compression systems [6]. In general, liquid-toliquid systems are better suited for implementing glide matching than air-to-air systems [7]. The actual performance gain through glide matching, however, is largely a matter of achieving the right combination of heat exchanger sizing, selections of HTF and refrigerant [8].

When using a linear refrigerant and a HTF, perfect glide matching can only be obtained at one specific HTF flow rate [2]. This is usually estimated based on the heat transfer within the phase changing section considering the magnitude of TG at selected operating pressure (i.e. design conditions). Any subsequent change in the pressure or the HTF flow rate influence the degree of glide matching achievable.

The influence of the HTF flow rate on glide matching can be shown in Fig. 3, which presents 3 cases of different flow rates, plotting dT versus vapour quality.

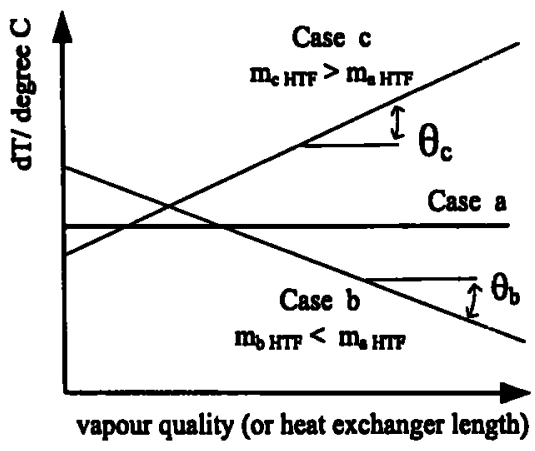

Fig. 3 : Degree of temperature glide match (relative to the cold end) [9]

When the HTF flow rate for obtaining TG match is not available, under or over glide condition occurs. A horizontal line (case a, Fig. 3) represents perfect TG match. For cases $b$ and $c$, the inclinations ( $b$ and (c correspond respectively to a certain degree of mismatch due to lower (i.e. $\mathrm{dT}$ is decreasing along the length, relatively to the cold end of the HTF) and higher flow rates (i.e. $\mathrm{dT}$ is increasing along the length) than that of case a. A large gradient implies a higher mismatch that generally leads to poor performance.

However, evaporator will not usually have the full glide corresponding to the operating pressure, due to the fact that the refrigerant is most likely to be in the two-phase state when entering the evaporator.

One implication of temperature glide is that at equal degree of condenser subcool (Fig. 4, point 7), with mixture a relatively larger portion of the refrigerant has evaporated during the isenthalpic expansion process. This means the vapour quality at evaporator entry (Fig. 4, point 1 ) is relatively higher when mixtures are used and it limits the amount of useful cooling the evaporator can do. Further, setting of cut-in and cut out temperatures of the compressor (controls) needs to take into account the magnitude of TG to achieve trouble free co-ordination between compressor and the rest of the system.

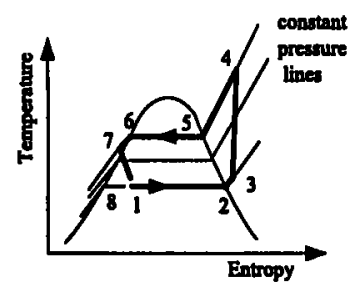

a) Pure fhids

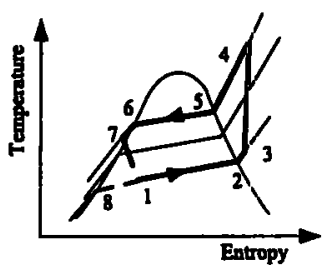

b) Mixturea
Fig. 4 : Vapour compression cycle on T-s plane 


\section{- Property non-linearity}

Enthalpy (or entropy) of a pure refrigerant during phase change is normally a linear function of vapour quality (vq), and is independent of the temperature as the process is isothermal [10]. In the case of zeotropic mixtures this fact does not hold true as the phase changing process is nonisothermal and the property can vary linearly or non-linearly with vapour quality (vq) and temperature ( $\mathrm{T})$.

Mixtures with larger glide tend to exhibit nonlinearities of two-phase properties, which can affect the overall glide situation of condenser or evaporator. As indicated in Fig. 5, due to property non-linearity, maintaining a constant $d T$ between the refrigerant and the HTF streams becomes difficult. Further, setting of the required HTF flow rate to achieve TG match will become difficult too $[2,11]$. In addition, due to the non-linearity, pinch points could occur within the phase changing section causing a reduction in the effectiveness of the heat transfer [12].

With certain zeotropes, depending on the boiling points and properties of the components, property (h or s) relationships with $\mathrm{T}$, and $\mathrm{T}$ with vq can show highly non-linear behaviour. Fig. 6 presents such a case (R23 and R142b) that shows non-linear relationships between enthalpy and vq with normalized $T$ at two selected compositions. In the figure, the normalized temperature on the horizontal axis is obtained using equation 1.

$$
T_{\text {normalized }}=\frac{T_{\text {two phase }}-T_{\text {buble }}}{T G}
$$

(1)

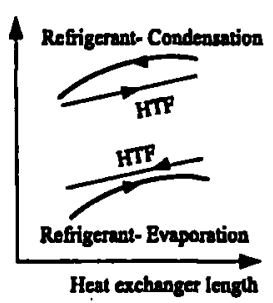

a) Non-linearity, type 1

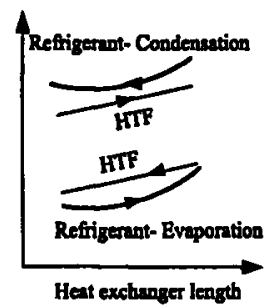

b) Non-linearity, type 2
Fig. 5 : Effect of property non-linearity on glide matching

Fig. 5 shows that in the presence of non-linearity the intermediate temperatures during phase change can be larger or smaller than the corresponding value if the properties were linear. This means the actual average effective $\mathrm{dT}$ within two-phase section can be larger or smaller than the designed/desired value. This seriously affects the accuracy of the NTU method [10], and the LMTD method based heat exchanger designs [13].
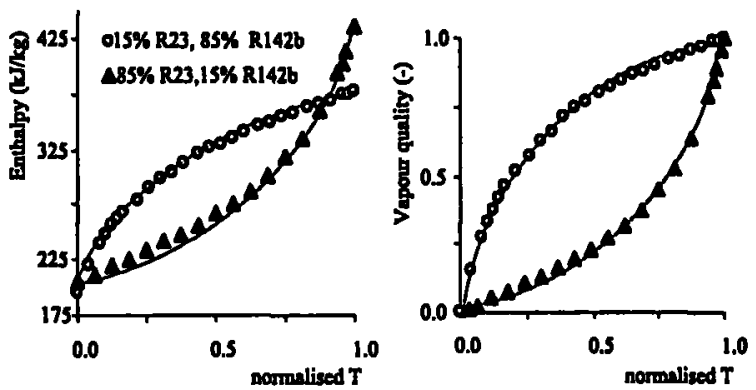

Fig. 6 : Two-phase non-linearity of refrigerant mixture [2]

Further, non-linearity could influence or limit the potential for decreasing the temperature differences at inlet/outlet, and may lead to increased heat transfer area requirement to achieve a desired capacity. Errors in the order of $50 \%$ in the heat exchanger area estimate could occur due to use of conventional LMTD method with non-linear mixtures [14].

\subsection{Shift in circulating composition}

When a vapour compression system uses a single component refrigerant, the concentration of the refrigerant through out the system remains the same. However, when zeotropes are used, researches have shown the existence of a running mixture composition different to the original mixture [15,16]. A different running composition exists due internal fractionation of zeotrpes [16] and hold up of liquid and vapour phases in twophase sections of heat exchangers and system components that hold refrigerant in equilibrium [17].

The fractionation is a result of preferential boiling (or condensation) of mixture components that result in different compositions in vapour and liquid phases during phase-change heat transfer. In boiling the vapour phase is usually enriched with more volatile components of the mixture while the liquid phase is depleted of the same. This situation results in holding up of less volatile components in the liquid phase during phase change while the circulating mixture composition within the system becomes different to that of original composition. In addition, shift in the circulating composition occurs due to refrigerant leakages (mostly in vapour phase) and differential solubility of mixture components in the lubricants [18]. 
Shift in circulating composition leads to modified system pressures, temperatures, capacity and efficiency [19], and the magnitude of which depends on the design and operational parameters of the system concern [16]. For a given refrigerant mixture and a system, the magnitude of the concentration shift varies with the amount of system charge, operating conditions, volumes of heat exchangers and the availability of liquid receiver and suction line accumulator. To estimate the circulation composition, refrigerant hold ups in different parts of the system (where the liquid and the vapour phases coexist) need to be estimated [17]. Refrigerant hold up estimate does not involve the single-phase sections such as suction and liquid lines.

\section{- Capacity control}

As indicated above, in normal system operation, the circulating mixture composition within the system is different to the original composition. In other words, if the running composition can be varied, the thermodynamic properties of the mixture can be altered providing an additional means of controlling the capacity.

Different methods can be employed to achieve the necessary changes in running composition. However, all these can be classified under two generic categories. Active systems, which use rectification, and passive systems that use accumulators [20].

Systems using passive techniques require a large amount of refrigerant charge and the potential of composition change is theoretically limited between dew and bubble line compositions [21]. Usually, the variation of composition resulting from refrigerant staying in various system components such as a liquid receiver or an accumulator is manipulated to change the system capacity with this method [20]. On the other hand, the achievable limit of capacity control in active systems depends on the effectiveness of rectifications and distillation process implemented within the system.

\subsection{Phase change heat transfer}

In vapour-liquid flow, the two phases exhibit various geometric configurations or flow regimes. During flow boiling or condensation, the HTC depends on the flow regime. Usually mixtures exhibit relatively lower HTCs compared to pure fluids

\section{- Condensation}

Condensation heat transfer behaviour of mixtures is quite complex. The effect of the mixture composition is complicated so that the HTC have not been found to vary in any familiar manner with the composition [22]. The mechanism of condensation is very sensitive to operating conditions and involve theoretically unexplained phenomenon [3].

Stratification of both the composition and the temperature in the vapour phase reduces the HTC [3]. In general, the stratification effects decreases as the vapour velocity increases. During condensation, more of the lower boiling components diffuse into the vapour away from the vapour-liquid interface. This mass fraction gradient creates a thermal gradient and mass transfer resistance in the vapour diffusion layer, affecting the condensation. This influence depends on the volatility difference between the mixture components. Further, in forced convection, composition of mixture, shape of surface and the velocity of the vapour influence the reduction in the HTC.

In addition, occurrence of concentration and temperature stratification due to the density differences of individual components (refrigerants) is another aspect that concerns with the phase change heat transfer behaviour of the refrigerants [3]. This situation causes degradation of convective heat transfer coefficient on refrigerant side.

With some mixtures (e.g. R22/R152a), the HTC is also a function of mass flux and the direction of vapour flow. During in tube condensation, the concentration of more volatile components increases in the vapour core along the flow direction. This causes a reduction of the bulk temperature of the vapour mixture, which degrades the HTC. [22].

\section{- Boiling and evaporation}

The presence of more than one component in mixture refrigerants changes the superheat required to initiate and sustain nucleation [23]. This change in the effective superheat is the main and the most complex contribution to the HTC degradation of mixtures [24]. Bubble growth during nucleation is limited by the fact that the liquid close to the bubble surface becomes depleted in the more volatile component. As 
shown in Fig. 7, in the case of a binary mixture, the minimum heat flux increases with the presence of an additional component. This indicates that relatively a higher amount of heat transfer and a larger wall superheat are required to initiate the boiling process [3]. These cause considerable reduction in nucleate boiling heat transfer.

HTC of mixture nucleate boiling is much lower than that of a pure refrigerant with similar physical properties, the deterioration increases with pressure, and does not change linearly with composition [25]. This HTC deterioration is mainly attributed to a rise of local boiling point temperature due to preferential evaporation during bubble formation and growth [26]. In addition, mass transfer resistance resulting from the concentration difference between vapour and liquid phases aggravate the heat transfer deterioration [27]. Similar to pool boiling, forced convective heat transfer of mixtures is also relatively poor.

It has been suggested that the mixture HTC is a function of the overall composition, and the physical properties account for $80 \%$ of heat transfer degradation seen in mixtures; the other $20 \%$ is considered to be due to the mass transfer resistance in convective region [28]. Degradation of HTC is also enhanced due to the non-linear mixture property behaviour. Further, the effect of mass flux has a large influence on the HTC due to the change in mass transfer resistance caused by the depletion of the more volatile components.

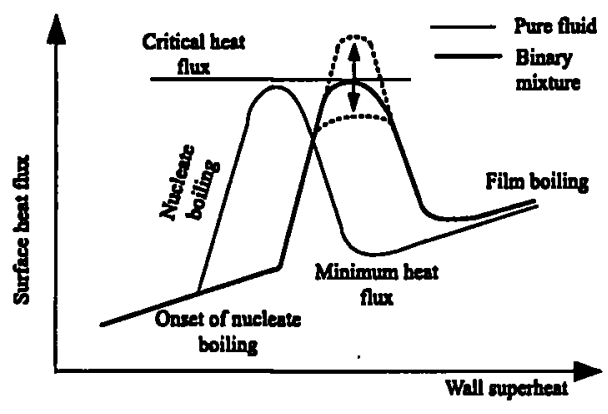

Fig. 7 : Principal changes to boiling curve for a binary mixture [24]

\subsection{Heat exchanger design for refrigerant mixtures}

LMTD and NTU-effectiveness $(\varepsilon)$ methods are the two conventional heat exchanger design methods. LMTD method requires the knowledge of all four temperatures (inlet and outlet) associated with the two fluids (the refrigerant and the HTF), whereas the NTU-E method uses the capacity rate (minimum of m.Cp of the two fluids) and heat exchanger effectiveness. Further, in both these design methods, the convective heat transfer coefficients and specific heat capacities (Cp) of the two fluids are assumed constants for the entire heat exchanger. However, for designs involving phase changing flow, the magnitude of HTC can vary by a factor of several times, and $\mathrm{Cp}$ does not remain constant as it is not directly related to the temperature change due to the contribution of the latent heat [29]. As the $C p$ is ideally infinite during condensation and evaporation, the minimum heat capacity rate usually refers to the HTF for designs (conventional) involving phase change heat exchangers.

When using the LMTD or NTU method, zeotropes encounter several unconventional problems. Because (1) phase change process is non-isothermal and (2) variation of $C_{p}$ and HTC of refrigerant side are relatively higher due to the effects of composition shift. If the temperature change during evaporation or condensation is proportional to enthalpy change (i.e. linear properties), the heat exchangers can be analyzed as an ordinary heat exchanger of fluids with varying temperature [29]. However, non-linear property behaviour of certain mixtures violates the assumptions of LMTD and NTU methods.

In the presence of varying specific heat capacity (linearly or non-linearly), the conventional NTU formulation needs correction as the minimum (or lesser) value of the heat capacity rate could refer to either the HTF or the phase changing refrigerant depending on flow conditions. If the mixture is non-linear, the situation is further aggravated, as the fluid having the minimum heat capacity rate could be the refrigerant at one point and the HTF at another point along the heat exchanger.

On the other hand, LMTD method can be used in the presence variable $\mathrm{Cp}$ and non-linearity using segments. Heat transfer in each segment is estimated based on the average values of refrigerant properties and heat transfer coefficients for each segment [14].

An alternative and better approach for computing heat exchanger parameters under varying HTC and $C p$ would be to use integration of the 
performance of small individual elements [2, 29]. A linearize temperature profile is assumed within each element to compute heat transfer coefficients. With a sufficient number of elements, this approach accounts for most of the local property variations and minimize the errors that would have occurred as a result of the use of the conventional design methods.

\section{Concluding remarks}

The paper highlighted few operational and design issues associated the use of zeotropic mixtures in vapour compression systems. These novel issues are expected to be taken into consideration either in designing new vapour compression systems or in retrofitting existing systems run on CFCs. Particularly, the retrofit aspect is quite applicable to our country so that knowledge on the behaviour of zeotrpes could be very useful in trouble shooting of retrofitted systems. Further, completely new design can include additional criteria that integrate TG and CS with a view to improve performance and energy efficiency (or $\mathrm{COP}$ ) of vapour compression systems

\section{References}

1. Rajapaksha L, Colbourne D and Suen K O, Size matching consideration during replacement of the condensing unit, Proc. of Ninth international refrigeration and air conditioning conference at Purdue, USA, 2002.

2. Rajapaksha L, Performance evaluation of reversible heat pumps when using refrigerant mixtures, PhD theses, University of London, 2003.

3. Wang, S and Chato J C, (a) Review of recent research on heat transfer with mixtures, Part 1: Condensation, ASHRAE Transactions, 1995, Vol. 101, Part 1, pp. 1376 -1386, Part 2: boiling and evaporation, ASHRAE Transactions, Vol. 101, Part 1, 1995, pp. 1387 - 1401.

4. Didion D A and Bivenns D B, The role of refrigerant mixtures as alternatives, Proc. ASHRAE 1989 CFC technology conference, NIST, Maryland, pp 57-69.

5. Stuart C F, Murphy $T$ and Wilkinson S, Composition shifts of zeotropic HFC refrigerants in service, ASHRAE Transactions, 1994, Vol. 100, Part 2, pp. 538 - 546.

6. Mulroy W J Domanski PA and Didion D A, Glide matching with binary and ternary zeotropic refrigerant mixtures, Part 1 An experimental study, Int. J. Refrig., Vol. 17, No. 4, 1994, pp 220 225.
7. Marques $\mathbf{M}$ and Domanski $\mathbf{P}$ A, Potential coefficient of performance improvements due to glide matching withR407C, Proc. Seventh Int. Refrig. Conf, Purdue, 1998, pp 101 - 108.

8. Haselden G G and Carter $K$, The case of wideboiling refrigerant mixtures for air-conditioning, Advance proof, Proc. Inst of ref, UK, session 1998 -99 (2).

9. Rajapaksha L and Suen $\mathrm{KO}$, Influence of reversing methods on the performance of a reversible waterto-water heat pump, Applied thermal engineering, Vol. 23, 2003, 49 - 64.

10. Granryd E, Conklin J C, Thermal performance analysis for heat exchangers using nonazeotropic refrigerant mixtures, ASME Symp. on heat transfer in advanced energy systems, Dallas, 1990, HTD - Vol. 151, pp. 25 - 32.

11. Venkatarathnam $G S$ and Sirinivasa $M$, Effect of mixture composition on the formation of pinch points in condensers and evaporators for zeotropic refrigerant mixtures, 1999, Int. J. Refrigeration, Vol. 22, pp. 205 - 215.

12. Venkatarathnam $G$, Mokashi $G$ and Sirinivasa $M$, Occurrence of pinch points in condensers and evaporators for refrigerant zeotropic mixtures, 1996, Int. J. Refrigeration, Vol. 19, No 6, pp. 361 368.

13. Liu $X$, Efficiency of non-azeotropic refrigeration cycles, International Refrigeration Conference at Purdue, 1998, pp 109 -114.

14. Schaefer L A and Shelton S V, Heat exchanger mean temperature differences for refrigerant mixtures, Proc of the ASME advanced energy system division, ASE - Vol. 38, 1998

15. Kruse H, Kuver M, Quast U, Schroeder $M$ and Upmeier B, Theoretical and experimental investigations of advantageous refrigerant mixture applications, ASHRAE Transactions, Vol. 91, Part 2B, 1985, pp. 1383 - 1418.

16. Kruse $\mathrm{H}$ and Wieschollek $\mathrm{F}$, Concentration shift when using refrigerant mixtures, ASHRAE Transactions, 1997, Vol. 103, Part 1, pp. 747-755.

17. L Rajapaksha, $\mathrm{K} O$ Suen, Influence of liquid receiver on the performance of reversible heat pumps using refrigerant mixtures, International Journal of Refrigeration, Vol. 27, Issue 01, 2004, pp 53 - 62.

18. Johansson $A$ and Lundqvist $P, A$ method to estimate the circulated composition in refrigeration and heat pump systems using zeotropic refrigerant mixtures, Int. J. Refrig., Vol. 24, No. 8, 2001, pp 798 - 808. 
19. Chen $J$ and Kruse $H$, Calculating circulation concentration of zeotropic refrigerant mixtures, HVAC\&R Research, 1995, Vol. 1, No 3, pp. 219. 231.

20. Radermacher $R$ and Hwang $Y$, Vapour Compression heat pumps with refrigerant mixtures, 2000, Dept. of Mechanical Eng., University of Maryland, USA.

21. Rothfleisch P I, A simplified method of composition shifting with a distillation column for a heat pump employing a zeotropic refrigerant mixture, NISTIR 5689, 1995, National Institute of standards and technology, USA.

22. Tandon T N, Varrma H K and Gupta C P, Generalized correlation for condensation of binary mixtures inside a horizontal tube, Int. J. Refrig., Vol. 9, 1986, pp. 134 -136.

23. Shock RA W, Nucleate boiling in binary mixtures, International Journal of heat mass transfer, Vol. 20, 1977, pp. 701 - 709.

24. Collier J G and Thome J R, Convective boiling and condensation, Third edition, 1996, Clarendon Press, Oxford.
25. Thome J R, Boiling of new refrigerants: a state-ofthe-art review, Int. J. Refrig., Vol. 19, No 7, 1996, pp. 435 - 457.

26. Schlunder E U, Heat transfer studies - Nucleate boiling of mixtures, 8th International Heat transfer conference, San Francisco, 1986, Vol. 4, pp 2073 2079.

27. Alpay $\mathrm{H}$ E and Balkan F, Nucleate pool boiling performance of acetone-ethanol and methylene chloride ethanol binary mixtures, Int. J. Heat mass transfer, 1989, Vól. 32, No 12, pp. 2403 - 2408.

28. Jung D S, McLinden $M$, Radermacher $R$ and Didion D A, A study of flow boiling heat transfer with refrigerant mixtures, International Journal of Heat mass transfer, Vol. 32, No.9, 1989, pp. 1751 1764.

29. Granryd E, Conklin J C, Thermal performance analysis for heat exchangers using nonazeotropic refrigerant mixtures, ASME Symp. on heat transfer in advanced energy systems, Dallas, 1990, HTD - Vol. 151, pp. 25 - 32. 